\title{
Torque steadiness and muscle activation are bilaterally impaired during shoulder abduction and flexion in chronic post-stroke subjects
}

\author{
Gabriela Lopes Santos a,*, Luisa Fernanda García-Salazar ${ }^{a, b}$, Matheus Bragança Souza ${ }^{a}$, \\ Ana Beatriz Oliveira ${ }^{\mathrm{a}}$, Paula Rezende Camargo ${ }^{\mathrm{a}}$, Thiago Luiz Russo ${ }^{\mathrm{a}, *}$ \\ ${ }^{a}$ Department of Physiotherapy, Federal University of São Carlos (UFSCar), São Carlos, SP, Brazil \\ ${ }^{\mathrm{b}}$ Physical Therapy Program, School of Medicine and Health Science, University of Rosario, Bogotá, D.C., Colombia
}

\section{A R T I C L E I N F O}

\section{Article history:}

Received 30 March 2016

Received in revised form 30 June 2016

Accepted 5 July 2016

\section{Keywords:}

Paresis

Sensorimotor feedback

Upper extremity

Proprioceptive feedback

\begin{abstract}
A B S T R A C T
Objective: To characterize sensorimotor control and muscle activation in the shoulder of chronic hemiparetic during abduction and flexion in maximal and submaximal isometric contractions. Furthermore, to correlate submaximal sensorimotor control with motor impairment and degree of shoulder subluxation.

Methods: Thirteen chronic hemiparetic post-stroke age-gender matched with healthy were included. Isometric torques were assessed using a dynamometer. Electromyographic activity of the anterior and middle deltoid, upper trapezius, pectoralis major and serratus anterior muscles were collected. Variables were calculated for torque: peak, time to target, standard deviation (SD), coefficient of variation (CV), and standard error (RMSE); for muscle activity: maximum and minimum values, range and coefficient of activation. Motor impairment was determined by Fugl-Meyer and shoulder subluxation was measured with a caliper.

Results: Paretic and non-paretic limbs reduced peak and muscle activation during maximal isometric contraction. Paretic limb generated lower force when compared with non-paretic and control. Paretic and non-paretic presented higher values of SD, CV, RMSE, and CV for prime mover muscles and minimum values for all muscles during steadiness. No correlation was found between sensorimotor control, motor impairment and shoulder subluxation.

Conclusion: Chronic hemiparetic presented bilateral deficits in sensorimotor and muscle control during maximal and submaximal shoulder abduction and flexion.
\end{abstract}

(c) 2016 Elsevier Ltd. All rights reserved.

\section{Introduction}

Stroke is the second leading cause of death and the first of disability in the adult population (Feigin et al., 2014). Although spontaneous motor recovery can be observed in hemiparetic subjects, $50-70 \%$ of these individuals present residual deficits in the upper extremities even 2-4 years post-stroke (Hunter and Crome, 2002). These deficits may be related to sensorimotor control disruption that includes impairments in strength (Andrews and Bohannon, 2000; Avila et al., 2013; Colebatch and Gandevia, 1989; Jung et al., 2002; McCrea et al., 2003; Turner et al., 2012), proprioception (Niessen et al., 2008; Santos et al., 2015), coordina-

\footnotetext{
* Corresponding author at: Laboratório de Pesquisa em Fisioterapia Neurológica, Departamento de Fisioterapia, Universidade Federal de São Carlos (UFSCar), São Paulo, Rodovia Washington Luís, Km 235, Zip Code 13565-905, Brazil. (G.L. Santos).

E-mail address: gabrielalsantos@hotmail.com (G.L. Santos).
}

tion (Murphy et al., 2006), and muscle synergies (Rueda et al., 2012).

A good method to evaluate sensorimotor control during activities of the upper limbs is the steadiness assessment (Chow and Stokic, 2011). This test evaluates the muscle's ability to maintain and modulate submaximal torques over time, which affects the performance of activities of daily living (Chow and Stokic, 2011; Lodha et al., 2010). Some studies have identified that post-stroke individuals present deficits in sensorimotor control during submaximal activities of both lower (Chow and Stokic, 2011, 2013, 2014) and upper extremities (elbow, wrist, and fingers) (Lodha et al., 2013; Lodha et al., 2010; Naik et al., 2011), which are correlated with the degree of motor impairment (Lodha et al., 2010).

Likewise, understanding muscle activation patterns is also important to clarify the sensorimotor deficits present in this population, since fluctuations in force are related to alterations in muscle activation (Graves et al., 2000; Shinohara et al., 2003). During sustained submaximal voluntary contractions of wrist and elbow 
flexion, McNulty et al. (2014) observed that hemiparetic subjects (time post-stroke of 3-168 months) presented bilateral deficits in firing rate, discharge variability (coefficient of variation) and dynamic range of mean motor unit firing rates.

Appropriate sensorimotor control involves processing and integrating intact information from all of the sensory systems, including somatosensory systems. For example, proprioception has been reported as an important component in feedback and feedforward control during motor action (Riemann and Lephart, 2002a,b; Roijezon et al., 2015). In this sense, previous studies observed hemiparetics post-stroke presented bilateral proprioceptive deficits (Niessen et al., 2008; Santos et al., 2015). Furthermore, according to Santos and coworkers (Santos et al., 2015), higher the degrees of shoulder subluxation were correlated with higher absolute errors concerning the joint position sense (proprioceptive deficit). Both central and peripheral components seem to affect sensorial perception, processing and integration in post-stroke subjects, thus, it is reasonable to suppose that sensorimotor control, measured by steadiness assessment, might be bilaterally affected in shoulders of chronic post-stroke individuals and correlated with the degree of subluxation.

Although previous reports have already described bilateral deficits of upper limbs in post-stroke subjects, such as muscle weakness and altered sensibility, coordination and muscle synergy (Andrews and Bohannon, 2000; Avila et al., 2013; Colebatch and Gandevia, 1989; Jung et al., 2002; McCrea et al., 2003), no information is available about the ability of proximal upper limb musculature to generate and to sustain submaximal forces. This ability is important to provide stability during functional situations, for example for reaching objects. Steadiness test has been used to evaluate dexterity in different populations, such as athletes (Saccol et al., 2014; Zanca et al., 2013), individuals with Parkinson's disease (Robichaud et al., 2005; Rose et al., 2013), older adults (Chung-Hoon et al., 2016; Holmes et al., 2015) and cerebral palsy (Bandholm et al., 2009), demonstrating its reliability and validity. Evaluating the ability to generate and maintain submaximal torque over time, this study attempted to mimic functional situations, when proximal upper limb muscle activation and maintenance are required, for example for reaching objects. In addition, electromyography can indicate how shoulder control is disturbed during these tasks, showing evidence of neural strategies for sensorimotor control of proximal musculature of the shoulder.

Therefore, the main purpose of this study was to evaluate the changes in sensorimotor control and muscle activation in the shoulder complex of chronic hemiparetic post-stroke individuals during abduction and flexion in two different situations: (1) maximal voluntary isometric contractions and (2) submaximal isometric contractions with target torque. A secondary purpose was to determine whether there is a correlation between sensorimotor performance and motor impairment, and shoulder subluxation grade. The following hypotheses were tested: (1) reduced force generation and accuracy, increased variability, and altered muscle activation would be observed in the paretic and non-paretic sides when compared to control; (2) sensorimotor performance would be negatively correlated with motor impairment, and shoulder subluxation grade.

\section{Methods}

The cross-sectional study was approved by the Human Research Ethics Committee of the University (report \#112.551/2012), pursuant to National Health Council Resolution 466/2012. The sample size was calculated from the first ten subjects evaluated in this study (five hemiparetics and five healthy control subjects). The root mean square error of submaximal torque during flexion shoul- der was the main outcome measure. G.Power 3.1 software was used and a power of 0.80 and $5 \%$ of significance was set.

\subsection{Participants}

Participants aged 40-75 years were recruited from the local community. The recruitment period was from January to July 2014. The study procedures were explained to all participants, and written informed consent was obtained from all of them. The following inclusion criteria were considered for the Hemiparetic Group (HG): 6 months or longer post-stroke; one or more ischemic strokes in the same hemisphere determined by magnetic resonance imaging (MRI); spasticity score $\leqslant 2$ on the Modified Ashworth Scale (MAS); ability to perform shoulder flexion and abduction $\geqslant 45^{\circ}$ voluntarily; and adequate control of the trunk confirmed by the individual's ability to maintain a sitting posture without the support of the trunk and arms for one minute. Because there is no consensus in the literature about sensorimotor impairments due to type of stroke, this study considered just ischemic etiology.

The Control Group (CG) consisted of healthy subjects (Booth and Lees, 2006) matched for gender and age with individuals in the HG and with a score of $\geqslant 9$ in the Basal Physical Activity Questionnaire, indicating that they were not sedentary (Baecke et al., 1982; Thorp et al., 2011). Sedentary behavior can be deleterious for skeletal muscle constitution and also for neuromuscular performance (Bogdanis, 2012). The participants from both groups presented Mini-Mental State Examination scores in accordance with their personal educational levels (Brucki et al., 2003; Vilaro et al., 2007).

The exclusion criteria for both groups were as follows: severe cardiovascular diseases (heart failure, arrhythmias, angina pectoris, and acute myocardial infarction); neurological or orthopedic diseases; cognitive or communication impairments; any history of joint or muscle injuries of the shoulder complex or cervical joints (fractures or surgery); shoulder pain during the assessments; body mass index $>28 \mathrm{~kg} / \mathrm{m}^{2}$; and visual deficits. For the HG, individuals with other neurologic diseases, acute stroke, hemorrhagic stroke or any injury to the occipital lobe, brainstem, or cerebellum were also excluded. For the CG, individuals with unstable shoulders were excluded either if sulcus sign was present or apprehension test was positive (Wilk et al., 1997).

\subsection{Clinical assessment}

Participants were first submitted to an interview that included collection of personal data, physical examination and functional investigation. The clinical assessment was conducted by a single evaluator. The upper extremity motor impairment of the hemiparetic participants was assessed by the Fugl-Meyer Assessment (FMA) (Maki et al., 2006). They were also assessed for the presence of shoulder subluxation, which was quantified by determining the distance between the lateral edge of the acromion and the upper edge of the humeral head using a caliper. Based on the distance, the subluxation was graded as $0,1+, 2+$ or $3+$ for distances of $<0.5 \mathrm{~cm}, 0.5$ to $1 \mathrm{~cm}, 1-2 \mathrm{~cm}$, or $>2 \mathrm{~cm}$, respectively (Boyd et al., 1993). This measurement was performed in the two-day evaluation (clinical assessment and peak torque/steadiness torque) by the same evaluator in order to perform the reliability of intrarater measure. The reliability for the caliper subluxation measure was determined by calculating Intraclass Correlation Coefficient (ICC) and it was 0.97. Finally, both groups were assessed for manual preference by the Edinburgh Handedness Inventory (Oldfield, 1971). For HG, manual preference before stroke was considered. 


\subsection{Peak torque and sensorimotor control measurement}

After one week, peak torque and sensorimotor control (steadiness test) were measured during isometric abduction and flexion of the shoulder using a dynamometer (Biodex Multi-joint System 3, Biodex Medical System Inc., New York, NY, USA). The equipment was calibrated before each evaluation session as recommended by the manufacturer. The sampling frequency was set at $100 \mathrm{~Hz}$. Participants were seated in a dynamometer chair in accordance with previous studies (Avila et al., 2013; Santos et al., 2015).

Initially, three maximal voluntary isometric contractions (MVIC) were performed for $5 \mathrm{~s}$ at $45^{\circ}$ of abduction or flexion, with an interval of 2 min between trials, to determine peak torque. The highest peak torque of the three trials was used to calculate the target torque (35\% MVIC) (Camargo et al., 2009). According to Slifkin and Newell (1999), motor performance is enhanced when force increases to $30-40 \%$ of maximal voluntary contraction. Target torque was calculated by following formula: [(peak torque - limb weight) $* 0.35]+$ limb weight (Camargo et al., 2009). Afterwards, four trials of $10 \mathrm{~s}$ were performed at the target torque in order to evaluate sensorimotor control in submaximal isometric contractions. During each trial, the subjects were instructed to look at the monitor for visual feedback, aiming to achieve and maintain the target torque (Supplementary material). A rest period of 2 min was allowed between trials. The order of assessment of both the upper extremities and tasks (abduction and flexion) was randomized in both groups to prevent possible learning effects.

Data analysis was performed considering the last three trials, the first trial was used as familiarization. Trials of submaximal isometric contractions were divided into 2 moments: the first three seconds, classified as 'adjustment phase', and the last $7 \mathrm{~s}$, ordered as 'steadiness phase' (Lavender and Nosaka, 2007). For adjustment phase, the time to reach the target torque was calculated. For steadiness phase, the following outcomes were analyzed: standard deviation (SD), coefficient of variation (CV), and root mean square error (RMSE). In few words, SD of torque is an absolute measure of variability, calculated by square root of torque variance (Camargo et al., 2009; Lodha et al., 2010; Tracy et al., 2015); CV of torque is a measure of variability (normalized measure), which consists of the ratio between the standard deviation and the mean torque generated $(C V=S D /$ mean torque $\times 100$ ) (Camargo et al., 2009; Krishnan et al., 2011; Lodha et al., 2010; Tracy et al., 2015); and RMSE is the square of the vertical distance between the target torque and torque produced (Lodha et al., 2010). All data were reduced using Matlab software (version 7.0.1, MathWorks Inc., Natick, MA, USA).

\subsection{Assessment of muscle activity - electromyography}

Electromyographic (EMG) activity was bilaterally recorded, simultaneously to the peak torque and sensorimotor control assessment measurement using a Trigno $^{\mathrm{TM}}$ Wireless System (Delsys, Boston, MA, USA). For abduction, the activation of the upper trapezius (UT), serratus anterior (SA), and middle deltoid (MD) muscles were investigated; and for flexion, the activation of upper trapezius (UT), anterior deltoid (AD), and pectoralis major (PM) muscles were considered. Each electrode pre-amplified the signal and was interfaced to an amplifier unit (Delsys, Inc, Boston, MA, USA, common-mode rejection ratio of $80 \mathrm{~dB}$; band pass of $20-450 \mathrm{~Hz}$ ). Sampling frequency was set at $1000 \mathrm{~Hz}$ per channel.

The electrode of the upper trapezius was placed $2 \mathrm{~cm}$ lateral to the midpoint between the $\mathrm{C} 7$ and the acromion (Jensen et al., 1993). The serratus anterior electrode was placed below the axillary area, at the level of the inferior tip of the scapula, and medial to the latissimus dorsi (Park et al., 2013). The pectoralis major electrode was attached approximately $2 \mathrm{~cm}$ away from the axillary fold
(Park et al., 2013). The anterior deltoid electrode was placed one finger width distal and anterior to the acromion (Hermens et al., 1999). The medium deltoid electrode was placed between the acromion and lateral epicondyle of the elbow which corresponds to the greatest bulge of the muscle (Hermens et al., 2000).

The time series of the torque data were low-pass filtered using a fourth-order zero-lag Butterworth filter at $20 \mathrm{~Hz}$. The EMG signals were corrected for offset and band-pass filtered at $20-450 \mathrm{~Hz}$, also through a fourth-order zero-lag Butterworth filter. The RMS was obtained by the windowing process (Silva-Couto et al., 2014). During maximal voluntary isometric contractions, peak muscle activation (peak MVIC), in millivolts, was calculated for the active and non-active sides. For submaximal isometric contractions, just the steadiness phase was considered, and the following variables were calculated for the active limb: coefficient of variation ( $C V=$ $\mathrm{SD} /$ mean activation $\times 100$ ), maximum (Max $=$ highest value), minimum (Min = lowest value), and range of activation (Range = Max-Min). CV of activation is a normalized measure, which quantifies total variability as a fraction of the mean activation exerted. All data were reduced using Matlab software (version 7.0.1, MathWorks Inc., Natick, MA, USA).

\subsection{Statistical analysis}

All statistical tests were performed using SPSS software version 17.0 (SPSS Inc, Chicago, IL, USA). The unpaired $t$ test was used to compare age, weight, height, and body mass index between groups. Peak torque and sensorimotor control data showed normality and homoscedasticity ( $p>0.05$ ), according to Shapiro Wilk and Levene tests, respectively. Initially, the paired $t$ test was used to compare each participant's dominant and non-dominant sides for peak torque, variables of adjustment phase (time to target torque), and steadiness phase (SD, CV, and RMSE) during each test. Thus, as no differences were observed between limbs in the control group for these variables, a pool of data from both limbs was used as a control, as done previously in other studies (Santos et al., 2015; Silva-Couto et al., 2014). One-way ANOVA (Factor: Limb; control, paretic, and non-paretic) followed by the Tukey's posthoc was used for all above variables during each test. An alpha level was set at 0.05 with a $95 \%$ confidence interval.

EMG data did not show normality and homoscedasticity when submitted to the same tests, therefore the Wilcoxon test was used to compare each participant's dominant and nondominant limbs. Thus, as no differences were observed between limbs in the control group, a pool of data from both limbs was used as a control. The Kruskal Wallis test was used to verify differences among paretic, non-paretic, and control for the EMG variables (peak MVIC, CV, Max, Min, Range). The same test was used to compare the peak of MVIC for non-active side. The Mann-Whitney test with Bonferroni adjustment $(p<0.017)$ was used as the post-hoc analysis.

Spearman's correlation was used to investigate the relationship between the variables of steadiness phase, the total FMA upper extremity score, and shoulder subluxation grade. The magnitude of the correlations was based on the Munro classification (Munro, 2005) and recorded as follows: low (0.26-0.49), moderate (0.50-0.69), high (0.70-0.89), or very high $(0.90-1.00)$. An alpha level was set at 0.05 with a $95 \%$ confidence interval.

\section{Results}

\subsection{Participants}

One hundred and twenty-three individuals were contacted to participate in the study ( $\mathrm{HG}=79 ; \mathrm{CG}=44$ ); however, only 26 
individuals (13 hemiparetics and 13 controls) completed all proposed assessments. Of the 97 excluded individuals, 21 did not answer the phone, 2 moved to another city, 42 declined to participate, 29 were excluded by exclusion criteria, and 3 gave up to after clinical assessment. The detailed Flow Chart is presented in the study by Santos et al. (2015). No differences were observed between groups for age, weight, height, or body mass index $(p>0.05)$. CG presented average age of $60.92( \pm 10.87)$ and body mass index of $25.13( \pm 1.84)$; and HG showed average age of $61.08( \pm 10.55)$ and body mass index of $25.33( \pm 2.19)$. Santos et al. (2015) present the detailed data about subject demographic and clinical characterization.

About HG, individuals presented mean of 45.67 months poststroke time ( $\mathrm{SD}=35.27$, range 9-132 months). The HG was composed of 7 individuals with chronic right hemiparesis and 6 with chronic left hemiparesis. Four chronic hemiparetic post-stroke individuals had no glenohumeral subluxation, however, 5, 3 and 1 have grades $1+, 2+$, and $3+$, respectively. Hemiparetic individuals were classified either as 0 or $1+$ on the MAS for both shoulders during flexion $(0, n=3 ; 1+, n=10)$ and abduction $(0, n=4 ; 1+, n=9)$. Furthermore, hemiparetics were characterized by a moderate motor impairment according to Fugl-Meyer (average 45.67, median 46).

\subsection{Peak torque and electromyographic activity during maximal voluntary isometric contractions}

Peak torque for abduction $\left(\mathrm{F}_{1,25}=10.01 ; \mathrm{p}<0.01\right)$ and flexion $\left(\mathrm{F}_{1,25}=12.51 ; \mathrm{p}<0.01\right)$ were reduced in both the paretic limb (abduction: $26.21 \pm 9.22 \mathrm{~N}$; flexion: $21.22 \pm 8.64 \mathrm{~N}$ ) and the nonparetic limb (abduction: $33.13 \pm 12.73 \mathrm{~N}$; flexion: $35.46 \pm 13 \mathrm{~N}$ ) compared with control (abduction: $46.34 \pm 12.64 \mathrm{~N}$; flexion: $42.21 \pm 10.69 \mathrm{~N} ; \mathrm{p}<0.05)$. Furthermore, the paretic limb presented the lowest values of isometric peak torque compared to the nonparetic limbs and controls ( $\mathrm{p}<0.05)$.

For active limbs during both tasks, the peak MVIC of MD, AD, UT, $\mathrm{PM}$, and SA was lower in the paretic and non-paretic limb compared with control ( $\mathrm{p}<0.05$; Fig. $1 \mathrm{~A}$ and $\mathrm{B})$. Moreover, no differences between the paretic and non-paretic limbs were found $(p>0.05$; Fig. 1A and B). The same pattern was observed for muscle activation of non-active limbs during abduction and flexion (Fig. 1C and D).

\subsection{Torque variation during the adjustment and steadiness phases}

Graphic representations of the control, non-paretic, and paretic limbs are shown in Fig. 2(A-C). For the adjustment phase, the time to target torque was lower for the control and non-paretic limbs compared to the paretic limb, with no difference between control and non-paretic. Regarding to steadiness phase, paretic and nonparetic limbs presented higher values of SD, CV and RMSE compared with the controls in both shoulder $(p<0.05$; Table 1$)$, but no difference was found between the paretic and non-paretic limbs ( $\mathrm{p}>0.05$; Table 1$)$.

\subsection{Muscle activity during steadiness phase}

No differences were found between the paretic, non-paretic, and control limbs for the maximum and range of any of the muscles during both tests ( $p>0.05$, data not presented). Nevertheless, the minimum values of MD, UT and SA during abduction as well as the minimum of $A D$ and $P M$ for flexion were higher in both the paretic and non-paretic limbs compared to controls $(p<0.05$; Fig. 3A and B), with no differences between paretic and nonparetic sides $(p>0.05)$. The values of $C V$ for MD during abduction and for PM during flexion were higher in the paretic and non-paretic limbs compared with the control limb, with no
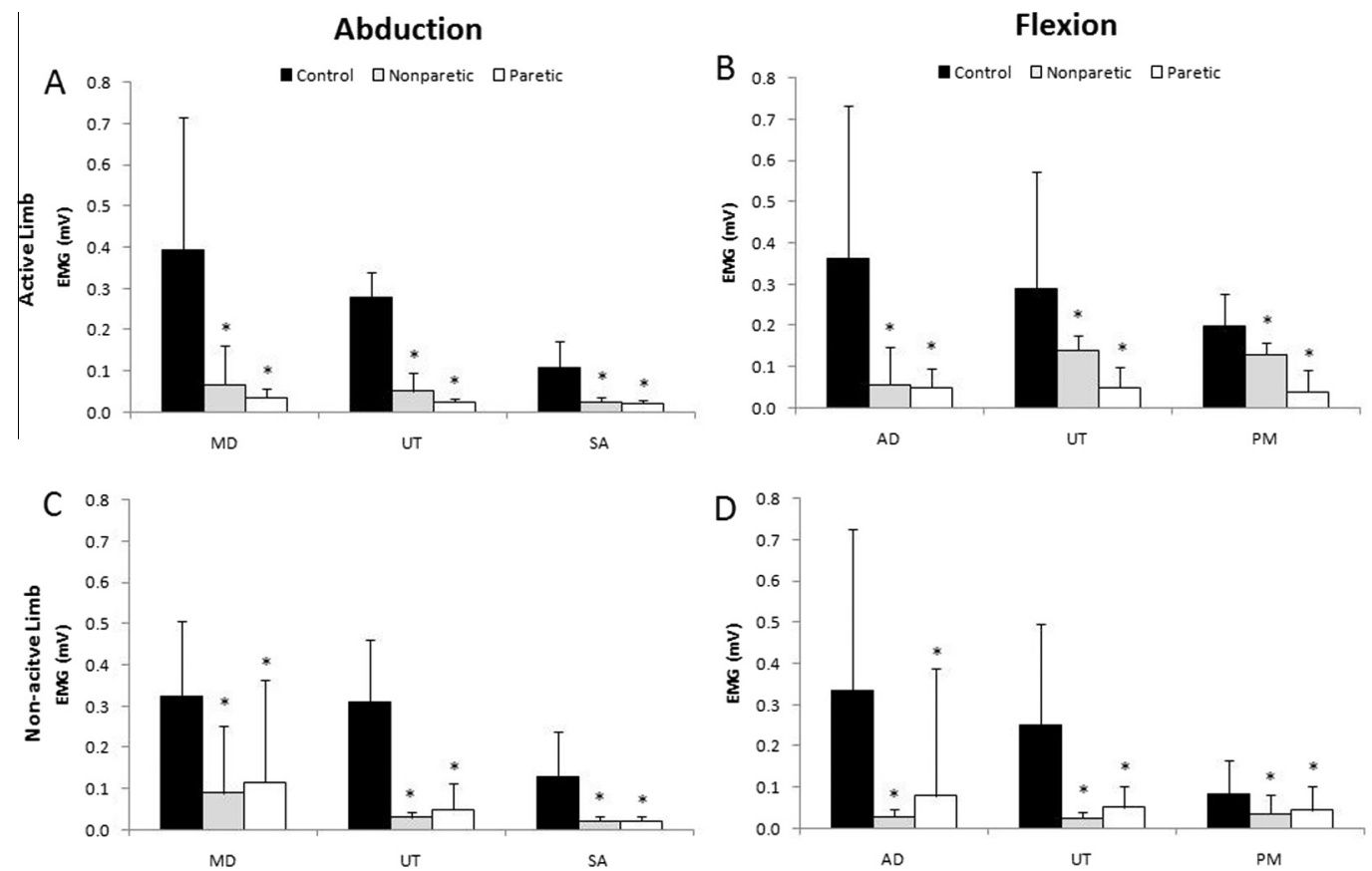

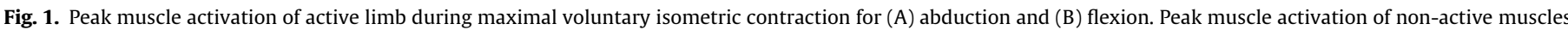

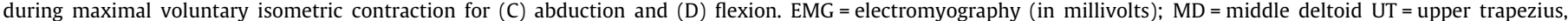

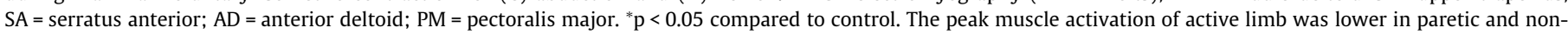

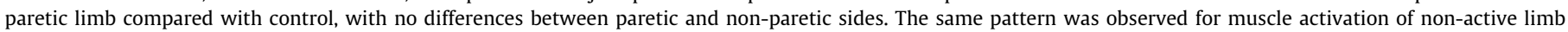
during abduction and flexion. 

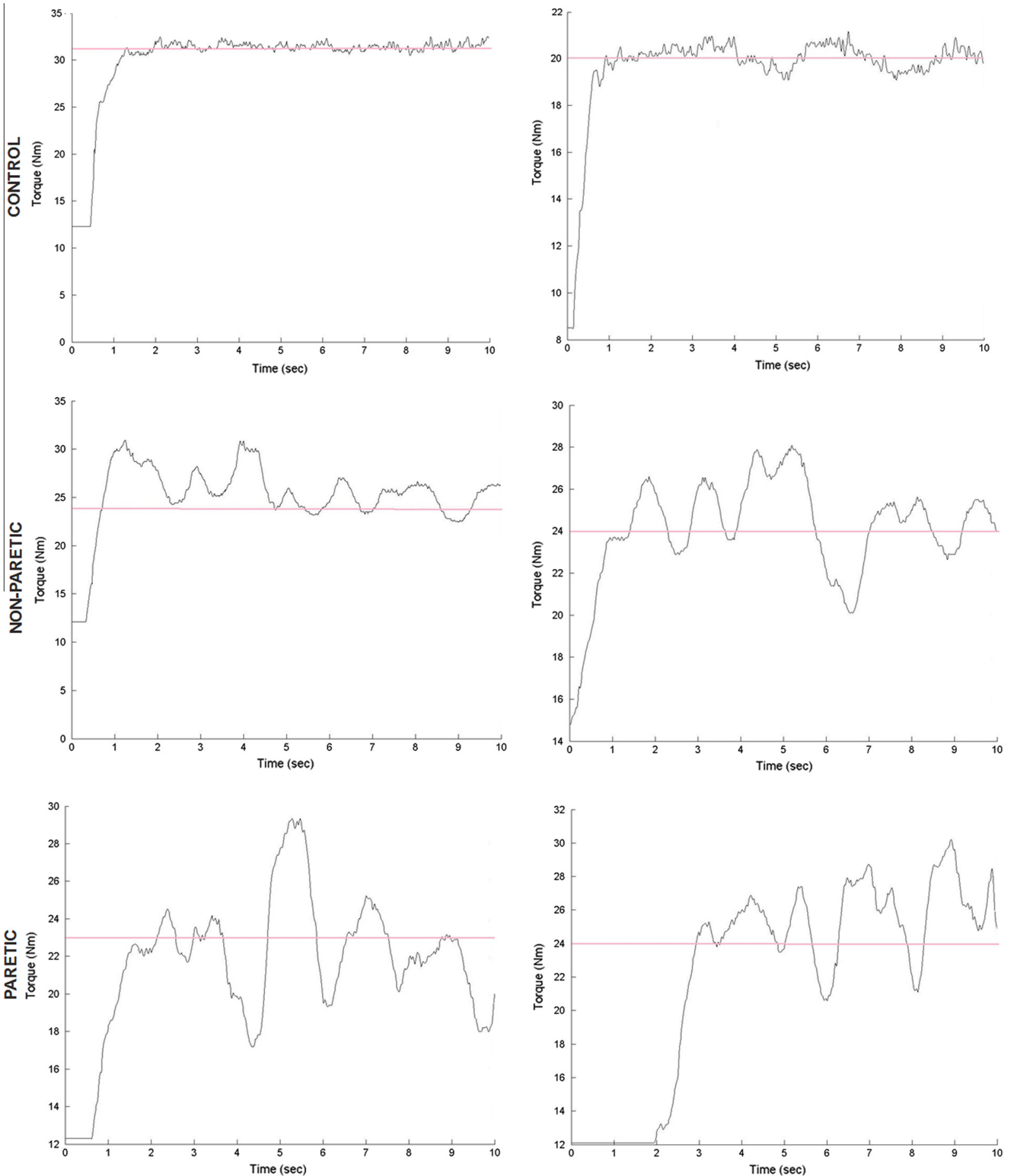

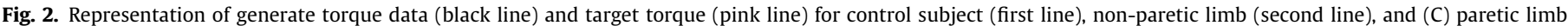

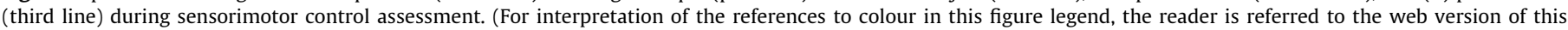
article.)

differences between paretic and non-paretic sides $(p>0.05$; Fig. 3C and D).

\subsection{Correlations}

The correlation between the torque variables of steadiness phases (CV, SD, and RMSE) and the total FMA upper extremity score, as well as the score of motor function subscale, and shoulder subluxation grade $(p>0.05)$ did not reach statistical significance with this sample size.

\section{Discussion}

The present study results showed that chronic hemiparetic post-stroke individuals presented reduced isometric peak torque as well as lower activation of the anterior deltoid, middle deltoid, upper trapezius, pectoralis major, and serratus anterior muscles during maximal isometric contractions on both sides, compared to healthy subjects. The paretic limb was slower to achieve the target torque compared to the non-paretic and control limbs, and sensorimotor performance was bilaterally impaired in 
Table 1

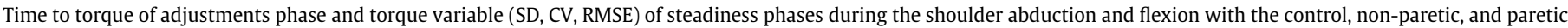
limbs. ${ }^{a}$

\begin{tabular}{|c|c|c|c|c|c|}
\hline \multirow[t]{2}{*}{ Measure } & & \multirow{2}{*}{$\begin{array}{l}\text { Adjustment Phase } \\
\text { Time to target (s) }\end{array}$} & \multicolumn{3}{|c|}{ Steadiness phase } \\
\hline & & & $\mathrm{SD}(\mathrm{Nm})$ & CV (\%) & RMSE (Nm) \\
\hline Abduction & $\begin{array}{l}\text { Control } \\
\text { Non-paretic } \\
\text { Paretic }\end{array}$ & $\begin{array}{l}0.96( \pm 0.17) \\
5.48( \pm 4.21)^{*} \\
8.53( \pm 6.53)^{*}, \dagger\end{array}$ & $\begin{array}{l}0.96( \pm 0.17) \\
5.48( \pm 4.21)^{*} \\
8.53( \pm 6.53)^{*}\end{array}$ & $\begin{array}{l}1.88( \pm 0.36) \\
7.76( \pm 5.51)^{*} \\
10.24( \pm 7.97)^{*}\end{array}$ & $\begin{array}{l}3.97( \pm 0.50) \\
4.27( \pm 0.66) \\
4.74( \pm 0.65)\end{array}$ \\
\hline Flexion & $\begin{array}{l}\text { Control } \\
\text { Non-paretic } \\
\text { Paretic }\end{array}$ & $\begin{array}{l}0.88( \pm 0.19) \\
1.43( \pm 1.05)^{*}, \dagger \\
2.21( \pm 1.46)^{*}\end{array}$ & $\begin{array}{l}0.88( \pm 0.19) \\
1.43( \pm 1.05)^{*} \\
2.21( \pm 1.46)^{*}\end{array}$ & $\begin{array}{l}1.91( \pm 0.51) \\
10.87( \pm 6.36)^{*} \\
11.97( \pm 7.95)^{*}\end{array}$ & $\begin{array}{l}3.51( \pm 0.53) \\
4.17( \pm 0.69) \\
4.44( \pm 0.64)\end{array}$ \\
\hline
\end{tabular}

a Measurements are reposted as mean and standard deviation.

Significantly different compared with control limb $(\mathrm{p}<0.05)$.

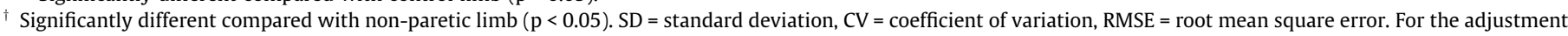

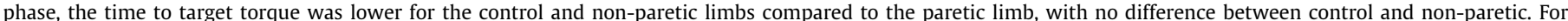

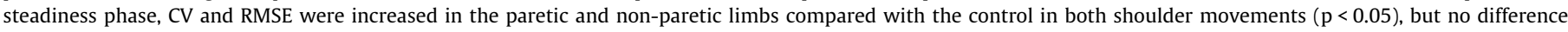
between paretic and non-paretic limb was found.

chronic hemiparetic post-stroke individuals during submaximal isometric contractions, represented by higher values of SD, RMSE, and CV compared to healthy individuals during steadiness phase. Furthermore, during the steadiness phase, chronic hemiparetic post-stroke individuals showed higher minimum values of muscle activation for all analyzed muscles, as well as higher CV of agonist muscles during abduction and flexion in the paretic and nonparetic limbs.

\subsection{Deficits in torque and muscle activation during maximal isometric contractions are bilateral in chronic hemiparetic post-stroke individuals}

The present study demonstrated that chronic hemiparetic poststroke individuals have bilateral weakness associated with muscle activation deficits during maximal isometric contractions (MVIC) of abduction and flexion of the shoulder compared to healthy individuals, which corroborates previous studies (Lodha et al., 2010; Turner et al., 2012). In agreement with Avila et al. (2013), this bilateral reduction in force is related to lower agonist activation of the shoulder. These results may be explained by the changes in the central neural drive (Landau and Sahrmann, 2002; Lodha et al., 2010) and by the structural integrity damage of the corticospinal tract (Sterr et al., 2010). These alterations can lead to a decreased number of active motor units (MUs), discharge rate, and activation of motor units (Lukacs, 2005; Lukacs et al., 2008). Other factors can be involved in non-paretic deficits, like the presence of ipsilateral projections from the contralesional hemisphere (McNulty et al., 2014), hemispheric lateralization and asymmetry (Kwon et al., 2007) or evolving maladaptive changes in the intact hemisphere (Madhavan et al., 2010).

Furthermore, the weakness of trunk muscles (Likhi et al., 2013; Verheyden et al., 2007; Verheyden et al., 2006) can contribute for bilateral upper limbs deficits. In accordance with the literature
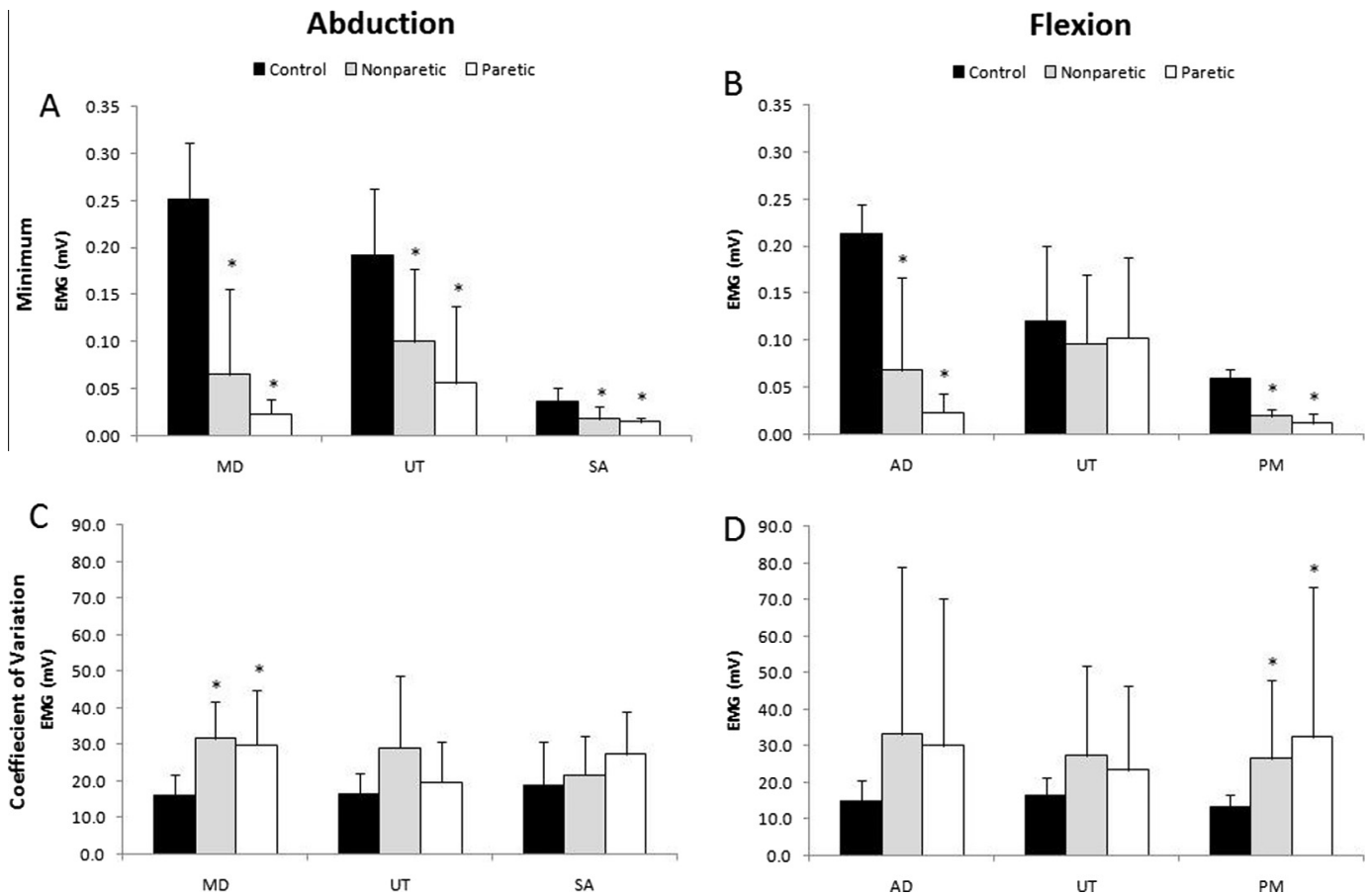

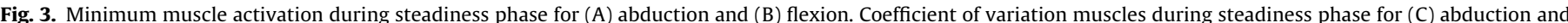

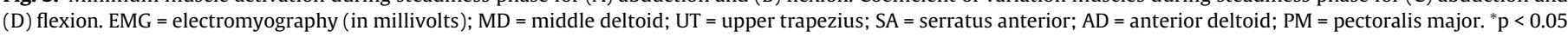

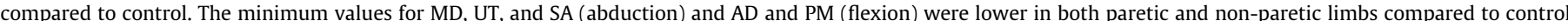

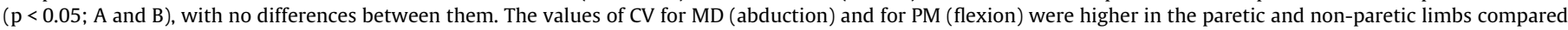
with the control limb, with no differences between them. 
(Jang et al., 2015; Likhi et al., 2013; Moezy et al., 2014), the scapula position and trunk stabilization are critical for appropriate glenohumeral function and shoulder movements, because they provide stability when performing upper extremity movements. Trunk stability plays an important role in load transfer to the limbs, helping the generation of force (Jang et al., 2015). This strategy to increase the stability of the scapular and trunk, also justifies the increased muscle activation of the non-active side of the control group, in order to increase the force generated during maximal activity (Jang et al., 2015).

Bilateral changes in chronic hemiparetic post-stroke individuals can also be explained a sedentary lifestyle. According to Tieges and coworkers (2015), hemiparetic subjects spend on average $81 \%$ of the time per day in sedentary behavior, and it is strongly correlated to less functional independence measured by the Nottingham Extended Activities of Daily Living Questionnaire (Tieges et al., 2015). Thus, being less active results in limited use of the upper limb in the activities of daily living, which can increased the bilateral weakness of chronic hemiparetic post-stroke individuals.

However, marked weakness was observed in the paretic limb, without differences between muscle activation of both sides in chronic hemiparetic post-stroke individuals. This result suggests that, in addition to MU deficits, agonist-antagonist coactivation (Holmes et al., 2015; Stoeckmann et al., 2009) and maladaptive intrinsic changes in the muscles (McNulty et al., 2014) may be present in these individuals, contributing to muscle weakness. According to previous studies, antagonist muscle coactivation could contribute to weakness through mechanical opposition of the agonist action (Kellis and Baltzopoulos, 1996) and to reciprocal inhibition of the agonist (Clark and Fielding, 2012). Regarding the anatomical changes in the paretic upper limb, it could be related to muscle atrophy (Ploutz-Snyder et al., 2006; Triandafilou and Kamper, 2012), caused by decreases in muscle fiber size (Li et al., 2007) and lean muscle mass (Carin-Levy et al., 2006). These alterations lead to modifications in functional properties of skeletal muscle (e.g. length-tension) that may influence the generation of force (Gray et al., 2012). Furthermore, this weakness can be related to disuse by the corticospinal tract lesion and decrease in muscle overload (Sions et al., 2012).

\subsection{Chronic hemiparetic post-stroke individuals presented bilateral deficits in sensorimotor control during submaximal isometric contractions}

In the adjustment phase, the paretic side was slower to achieve the target torque when compared to the non-paretic side and control, without differences between non-paretic and control. This slowness was also observed in a previous study characterized by a delayed onset muscle activation of the middle deltoid during shoulder abduction with the paretic limb (Avila et al., 2013). A previous study has already described that the weakness of the paretic side increases the time required to produce effective torque during a high-speed contraction (Enoka, 1997).

Furthermore, there is an increase and enlargement of the remaining MUs during the chronic stage of stroke due to degeneration of large motor neurons (high recruitment threshold) and selective failure of activation of the large MUs, and collateral sprouting begins to expand remaining units while the spontaneous activity does not appear (Lukacs, 2005; Lukacs et al., 2008). These changes in MUs can lead to the inability to discharge closely spaced action potentials at the beginning of quick force (Chou et al., 2013). Thus, considering that there is a shift from high- to low-threshold MUs in the paretic side, the generation of the remaining muscle force is compromised, slowing down voluntary movements (Lukacs et al., 2008).
Another important aspect of the study involves the comparison between non-paretic versus control limbs. Although both limbs presented a similar time to achieve the target torque, non-paretic limbs generated lower levels of absolute torque compared to the control. It is possible hypothesized that the non-paretic side presented reduced a capacity to change the rate of torque changes. In other words, when comparing the same period, hemiparetic subjects generate less torque compared with healthy controls. According to literature, the rate of torque changes can be affect by the number of MUs activated, the rate of motor neuron discharge, the capacity of muscle activation at the onset of contraction, and the ability to generate volitional drive in a brief period (Maffiuletti et al., 2016).

In relation to steadiness phase, the paretic and non-paretic upper extremities presented higher values of SD, CV, and RMSE compared to control without significant differences between them, which corroborates previous studies (Lodha et al., 2013, 2010). These higher values can be explained by muscle weakness (Lodha et al., 2010; Patten et al., 2003), an increase in the variability rates of active motor unit discharges (Enoka et al., 2003), a decrease in the degree of MU synchronization (Taylor et al., 2003), an altered modulation in the discharge of MU and discharge intervals (Chow and Stokic, 2011; Lodha et al., 2010), and a decrease in the range of motor unit discharge rates (Chou et al., 2013).

Electromyography findings showed that the CV of muscle activation for the MD and PM during abduction and flexion, respectively, presented higher values in paretic and non-paretic sides compared to control, corroborating the variability of the torque data. We observed this behavior in the prime mover of abduction, the MD (Phadke et al., 2009), which justified the higher variability in torque. However, for shoulder flexion, higher torque variability was only observed in the PM, which acts with the AD as a prime mover during shoulder flexion (Kapandji, 2000). According to Roh and colleagues (2013), stroke subjects presented alterations in muscle synergies during isometric force of shoulder and elbow joints with higher activation of PM and limited AD activation (Roh et al., 2013).

Furthermore, the paretic and non-paretic sides presented higher minimum values of muscle activation for all assessed muscles compared to control with no differences between paretic and non-paretic limbs. However, for maximum values and range of activation, no differences among control, non-paretic and paretic limbs were observed. In a study with elderly subjects during submaximal isometric contractions, the authors reported that older adults had more difficulty performing controlled reductions in muscle strength (Enoka, 1997). This aspect was observed by a greater SD for the lengthening contractions compared with the shortening contractions, which may be related to the use of different strategies of the central nervous system to control the eccentric and concentric contractions (Enoka, 1997). Thus, according to the results of the present studies and the presence of similar changes in MUs between elderly and post-stroke subjects, it is possible to suppose that chronic hemiparetic post-stroke individuals also presented inadequate modulation of muscle strength.

4.3. None of the torque variables of steadiness phase were correlated to post-stroke time,

\subsubsection{FMA score or degree of shoulder subluxation}

Another important result was the lack of correlation between steadiness variables and FMA. This result is not in line with previous study, which observed that error (SD) and variability (RMSE) increased during wrist and finger extension movements according to sensorimotor impairment quantified by FMA (Lodha et al., 2010). The difference between the present study and the study of 
Lodha can be explained by the upper limb joints evaluated (proximal versus distal joints), and by the number of tests for each joint performed during FMA. The FMA presents many tests for distal movements and few for proximal control, which may partially explain the lack of correlation. On the other hand, deficits of maximal force generation seem to be better correlated with sensorimotor impairments in post-stroke subjects than dexterity (Bohannon et al., 1991; Eng, 2004; Harris and Eng, 2007; Mercier and Bourbonnais, 2004), however comparative studies between force control outcomes should be conducted in the future to predict post-stroke recovery and impairment. The construct of these instruments used to evaluate the upper limbs in the neurorehabilitation field may not reflect the dexterity of the upper limb proximal joints properly.

Finally, although shoulder subluxation generates joint instability (Huang et al., 2012), no correlation between the torque steadiness variables during submaximal contractions (CV, SD and RMSE) and subluxation degree was observed in the present study. In addition, when comparing the different degrees of shoulder subluxation and subgroups with or without subluxation of the hemiparetic group, no differences were observed for these variables (data not shown), confirming that the subluxation did not influence the shoulder sensorimotor performance during submaximal isometric contractions. This result can be explained by the fact that this task does not require joint movements (Faulkner, 2003) and, despite the presence of subluxation, patients in this study did not experience pain. According to the literature (Manara et al., 2015; Vafadar et al., 2015), the subluxation may be associated or not with pain, which impairs performance and motor recovery after stroke. However, future studies that investigate the relationship between pain and sensorimotor performance in submaximal conditions are needed.

Even though descriptive data are presented here, they have implications for future studies and support previous reports (Patten et al., 2003). These results may have implications for the development of an exercise program for motor rehabilitation, which needs to include exercises with muscle strengthening and training of motor skills with fine adjustments. These adjustments may be related to force or joint position with or without visual feedback. In addition, these findings also point to towards training also involving the non-paretic limb during bilateral and simultaneous activities.

\subsection{Study limitations}

Limitations of this study include the small sample size and the lack of EMG signal of the antagonist muscle. Furthermore, the study characterized the sensorimotor control of a specific population, which limits the extrapolation of the results to patients with severe physical disabilities, individuals with post-hemorrhagic stroke, and young subjects.

Moreover, other limitations involve some alterations of chronic hemiparetic post-stroke individuals, such as impaired visual and motor processing (Chow and Stokic, 2013; Lodha et al., 2013) and bilateral proprioceptive deficits (Santos et al., 2015), which can impair adequate sensorimotor control. Thus, they may have difficulty in perceiving and/or making fine corrections in force output using the visual feedback (Chow and Stokic, 2013; Clark et al., 2015; Lodha et al., 2013; Roijezon et al., 2015).

\section{Conclusions}

Chronic hemiparetic post-stroke individuals presented bilateral deficits in sensorimotor control in the shoulder complex during abduction and flexion. Altered accuracy and increased variability in torque steadiness, as well as disturbed muscle activation, seem to contribute to disrupted sensorimotor control in this population.

\section{Conflict of interest}

No conflict of interest.

\section{Acknowledgments}

This study was supported by FAPESP (Fundação de Amparo à Pesquisa do Estado de São Paulo; process numbers: 2013/216213 and 2014/25845-6), CNPq (Conselho Nacional de Desenvolvimento Científico e Tecnológico), and CAPES (Coordenação de Aperfeiçoamento de Pessoal de Nível Superior).

\section{Appendix A. Supplementary material}

Supplementary data associated with this article can be found, in the online version, at http://dx.doi.org/10.1016/j.jelekin.2016.07. 003.

\section{References}

Andrews, A.W., Bohannon, R.W., 2000. Distribution of muscle strength impairments following stroke. Clin. Rehab. 14, 79-87.

Avila, M.A., Romaguera, F., Oliveira, A.B., Camargo, P.R., Salvini, T.F., 2013. Bilatera impairments of shoulder abduction in chronic hemiparesis: electromyographic patterns and isokinetic muscle performance. J. Electromyogr. Kinesiol.: Official J. Int. Soc. Electrophysiol. Kinesiol. 23, 712-720.

Baecke, J.A., Burema, J., Frijters, J.E., 1982. A short questionnaire for the measurement of habitual physical activity in epidemiological studies. Am. J. Clin. Nutr. 36, 936-942.

Bandholm, T., Rose, M.H., Slok, R., Sonne-Holm, S., Jensen, B.R., 2009. Ankle torque steadiness is related to muscle activation variability and coactivation in children with cerebral palsy. Muscle Nerve 40, 402-410.

Bogdanis, G.C., 2012. Effects of physical activity and inactivity on muscle fatigue Front. Physiol. 3, 142.

Bohannon, R.W., Warren, M.E., Cogman, K.A., 1991. Motor variables correlated with the hand-to-mouth maneuver in stroke patients. Arch. Phys. Med. Rehab. 72 $682-684$.

Booth, F.W., Lees, S.J., 2006. Physically active subjects should be the control group. Med. Sci. Sports Exerc. 38, 405-406.

Boyd, E.A., Goudreau, L., O'Riain, M.D., Grinnell, D.M., Torrance, G.M., Gaylard, A. 1993. A radiological measure of shoulder subluxation in hemiplegia: its reliability and validity. Arch. Phys. Med. Rehab. 74, 188-193.

Brucki, S.M., Nitrini, R., Caramelli, P., Bertolucci, P.H., Okamoto, I.H., 2003. Suggestions for utilization of the mini-mental state examination in Brazil. Arq. Neuropsiquiatr. 61, 777-781.

Camargo, P.R., Avila, M.A., de Oliveira, A.B., Asso, N.A., Benze, B.G., de Fátima, Salvini T., 2009. Shoulder abduction torque steadiness is preserved in subacromial impingement syndrome. Eur. J. Appl. Physiol. 106, 381-387.

Carin-Levy, G., Greig, C., Young, A., Lewis, S., Hannan, J., Mead, G., 2006. Longitudinal changes in muscle strength and mass after acute stroke. Cerebrovasc. Dis. (Basel, Switzerland) 21, 201-207.

Chou, L.W., Palmer, J.A., Binder-Macleod, S., Knight, C.A., 2013. Motor unit rate coding is severely impaired during forceful and fast muscular contractions in individuals post stroke. J. Neurophysiol. 109, 2947-2954.

Chow, J.W., Stokic, D.S., 2011. Force control of quadriceps muscle is bilaterally impaired in subacute stroke. J. Appl. Physiol. (Bethesda, Md: 1985) 111, 12901295.

Chow, J.W., Stokic, D.S., 2013. Impaired force steadiness is associated with changes in force frequency composition in subacute stroke. Neuroscience 242, 69-77.

Chow, J.W., Stokic, D.S., 2014. Variability, frequency composition, and complexity of submaximal isometric knee extension force from subacute to chronic stroke. Neuroscience 273, 189-198.

Chung-Hoon, K., Tracy, B.L., Dibble, L.E., Marcus, R.L., Burgess, P., LaStayo, P.C., 2016. The association between knee extensor force steadiness, force accuracy, and mobility in older adults who have fallen. J. Geriatric Phys. Ther. 39, 1-7 (2001)

Clark, D.J., Fielding, R.A., 2012. Neuromuscular contributions to age-related weakness. J. Gerontol. Series A, Biol. Sci. Med. Sci. 67, 41-47.

Clark, N.C., Roijezon, U., Treleaven, J., 2015. Proprioception in musculoskeletal rehabilitation. Part 2: clinical assessment and intervention. Manual Ther. 20, 378-387.

Colebatch, J.G., Gandevia, S.C., 1989. The distribution of muscular weakness in upper motor neuron lesions affecting the arm. Brain: J. Neurol. 112 (Pt 3), 749763.

Eng, J.J., 2004. Strength training in individuals with stroke. Physiother. Canada Physiother. Canada 56, 189-201. 
Enoka, R.M., 1997. Neural strategies in the control of muscle force. Muscle Nerve Suppl. 5, S66-S69.

Enoka, R.M., Christou, E.A., Hunter, S.K., Kornatz, K.W., Semmler, J.G., Taylor, A.M., et al., 2003. Mechanisms that contribute to differences in motor performance between young and old adults. J. Electromyogr. Kinesiol.: Official J. Int. Soc. Electrophysiol. Kinesiol. 13, 1-12.

Faulkner, J.A., 2003. Terminology for contractions of muscles during shortening, while isometric, and during lengthening. J. Appl. Physiol. (Bethesda, Md: 1985) 95, 455-459.

Feigin, V.L., Forouzanfar, M.H., Krishnamurthi, R., Mensah, G.A., Connor, M., Bennett, D.A., et al., 2014. Global and regional burden of stroke during 1990-2010: findings from the Global Burden of Disease Study 2010. Lancet (London, England) $383,245-254$.

Graves, A.E., Kornatz, K.W., Enoka, R.M., 2000. Older adults use a unique strategy to lift inertial loads with the elbow flexor muscles. J. Neurophysiol. 83, 2030-2039.

Gray, V., Rice, C.L., Garland, S.J., 2012. Factors that influence muscle weakness following stroke and their clinical implications: a critical review. Physiother. Canada Physiother. Canada 64, 415-426.

Harris, J.E., Eng, J.J., 2007. Paretic upper-limb strength best explains arm activity in people with stroke. Phys. Ther. 87, 88-97.

Hermens, H.J., Freriks, B., Disselhorst-Klug, C., Rau, G., 2000. Development of recommendations for SEMG sensors and sensor placement procedures. I. Electromyogr. Kinesiol.: Official J. Int. Soc. Electrophysiol. Kinesiol. 10, 361-374.

Hermens, H.J., Freriks, B., Merletti, R., Stegeman, D., Blok, J., Rau, G., et al., 1999 European Recommendations for Surface Electromyography. Roessingh Research and Development, Enschede.

Holmes, M.R., Gould, J.R., Pena-Gonzalez, I., Enoka, R.M., 2015. Force steadiness during a co-contraction task can be improved with practice, but only by young adults and not by middle-aged or old adults. Exp. Physiol. 100, 182-192.

Huang, S.W., Liu, S.Y., Tang, H.W., Wei, T.S., Wang, W.T., Yang, C.P., 2012. Relationship between severity of shoulder subluxation and soft-tissue injury in hemiplegic stroke patients. J. Rehab. Med. 44, 733-739.

Hunter, S., Crome, P., 2002. Hand function and stroke. Rev. Clin. Gerontol. 12, 68-81.

Jang, H.J., Kim, S.Y., Oh, D.W., 2015. Effects of augmented trunk stabilization with external compression support on shoulder and scapular muscle activity and maximum strength during isometric shoulder abduction. J. Electromyogr. Kinesiol.: Official J. Int. Soc. Electrophysiol. Kinesiol. 25, 387-391.

Jensen, C., Vasseljen, O., Westgaard, R.H., 1993. The influence of electrode position on bipolar surface electromyogram recordings of the upper trapezius muscle. Eur. J. Appl. Physiol. 67, 266-273.

Jung, H.Y., Yoon, J.S., Park, B.S., 2002. Recovery of proximal and distal arm weakness in the ipsilateral upper limb after stroke. NeuroRehabilitation 17, 153-159.

Kapandji, I., 2000. Articular Physiology. Guanabara Koogan, Rio de Janeiro.

Kellis, E., Baltzopoulos, V., 1996. Agonist and antagonist moment and EMG-angle relationship during isokinetic eccentric and concentric exercise. Isokinet. Exercise Sci. 6, 79-87.

Krishnan, C., Allen, E.J. Williams, G.N., 2011. Effect of knee position on quadriceps muscle force steadiness and activation strategies. Muscle Nerve 43, 563-573.

Kwon, Y.H., Kim, C.S., Jang, S.H., 2007. Ipsi-lesional motor deficits in hemiparetic patients with stroke. NeuroRehabilitation 22, 279-286.

Landau, W.M., Sahrmann, S.A., 2002. Preservation of directly stimulated muscle strength in hemiplegia due to stroke. Arch. Neurol. 59, 1453-1457.

Lavender, A.P., Nosaka, K., 2007. Fluctuations of isometric force after eccentric exercise of the elbow flexors of young, middle-aged, and old men. Eur. J. Appl. Physiol. 100, 161-167.

Li, L., Tong, K.Y., Hu, X., 2007. The effect of poststroke impairments on brachialis muscle architecture as measured by ultrasound. Arch. Phys. Med. Rehabil. 88, 243-250.

Likhi, M., Jidesh, V.V., Kanagaraj, R., George, J.K., 2013. Does trunk, arm, or leg control correlate best with overall function in stroke subjects? Top. Stroke Rehab. 20, 62-67.

Lodha, N., Misra, G., Coombes, S.A., Christou, E.A., Cauraugh, J.H., 2013. Increased force variability in chronic stroke: contributions of force modulation below 1 Hz. PLoS ONE 8, e83468.

Lodha, N., Naik, S.K., Coombes, S.A., Cauraugh, J.H., 2010. Force control and degree of motor impairments in chronic stroke. Clin. Neurophysiol.: Official J. Int. Federat. Clin. Neurophysiol. 121, 1952-1961.

Lukacs, M., 2005. Electrophysiological signs of changes in motor units after ischaemic stroke. Clin. Neurophysiol.: Official J. Int. Federat. Clin. Neurophysiol. 116, 1566-1570.

Lukacs, M., Vecsei, L., Beniczky, S., 2008. Large motor units are selectively affected following a stroke. Clin. Neurophysiol.: Official J. Int. Federat. Clin. Neurophysiol. 119, 2555-2558.

Madhavan, S., Rogers, L.M., Stinear, J.W., 2010. A paradox: after stroke, the nonlesioned lower limb motor cortex may be maladaptive. Eur. J. Neurosci. 32, 1032-1039.

Maffiuletti, N.A., Aagaard, P., Blazevich, A.J., Folland, J., Tillin, N., Duchateau, J., 2016 Rate of force development: physiological and methodological considerations. Eur. J. Appl. Physiol.

Maki, T., Quagliato, E., Cacho, E., Paz, L., Nascimento, N., Inoue, M., et al., 2006. Reliability study on the application of the Fugl-Meyer scale in Brazil. Braz. J. Phys. Ther. 10, 177-183.

Manara, J.R., Taylor, J., Nixon, M., 2015. Management of shoulder pain after a cerebrovascular accident or traumatic brain injury. J. Shoulder Elbow Surg./Am. Shoulder Elbow Surg. [et al.]. 24, 823-829.
McCrea, P.H., Eng, J.J., Hodgson, A.J., 2003. Time and magnitude of torque generation is impaired in both arms following stroke. Muscle Nerve 28, 46-53.

McNulty, P.A., Lin, G., Doust, C.G., 2014. Single motor unit firing rate after stroke is higher on the less-affected side during stable low-level voluntary contractions. Front. Human Neurosci. 8, 518.

Mercier, C., Bourbonnais, D., 2004. Relative shoulder flexor and handgrip strength is related to upper limb function after stroke. Clin. Rehab. 18, 215-221.

Moezy, A., Sepehrifar, S., Solaymani, Dodaran M., 2014. The effects of scapular stabilization based exercise therapy on pain, posture, flexibility and shoulder mobility in patients with shoulder impingement syndrome: a controlled randomized clinical trial. Med. J. Islamic Republic Iran 28, 87.

Munro, B.H., 2005. Statistical Methods for Health Care Research. Lippincott Williams \& Wilkins.

Murphy, M.A., Sunnerhagen, K.S., Johnels, B., Willen, C., 2006. Three-dimensional kinematic motion analysis of a daily activity drinking from a glass: a pilot study. J. Neuroeng. Rehab. 3, 18.

Naik, S.K., Patten, C., Lodha, N., Coombes, S.A., Cauraugh, J.H., 2011. Force control deficits in chronic stroke: grip formation and release phases. Exp. Brain Res. 211, 1-15.

Niessen, M.H., Veeger, D.H., Koppe, P.A., Konijnenbelt, M.H., van Dieen, J., Janssen, T. W., 2008. Proprioception of the shoulder after stroke. Arch. Phys. Med. Rehabil. 89, 333-338.

Oldfield, R.C., 1971. The assessment and analysis of handedness: the Edinburgh inventory. Neuropsychologia 9, 97-113.

Park, K.-M., Cynn, H.-S., Yi, C.-H., Kwon, O.-Y., 2013. Effect of isometric horizontal abduction on pectoralis major and serratus anterior EMG activity during three exercises in subjects with scapular winging. J. Electromyogr. Kinesiol. 23, 462468.

Patten, C., Kothari, D., Whitney, J., Lexell, J., Lum, P.S., 2003. Reliability and responsiveness of elbow trajectory tracking in chronic poststroke hemiparesis. J. Rehabil. Res. Dev. 40, 487-500.

Phadke, V., Camargo, P., Ludewig, P., 2009. Scapular and rotator cuff muscle activity during arm elevation: a review of normal function and alterations with shoulder impingement. Revista brasileira de fisioterapia (Sao Carlos (Sao Paulo, Brazil)) 13, 1-9.

Ploutz-Snyder, L.L., Clark, B.C., Logan, L., Turk, M., 2006. Evaluation of spastic muscle in stroke survivors using magnetic resonance imaging and resistance to passive motion. Arch. Phys. Med. Rehab. 87, 1636-1642.

Riemann, B.L., Lephart, S.M., 2002a. The sensorimotor system, part I: the physiologic basis of functional joint stability. J. Athletic Train. 37, 71-79.

Riemann, B.L., Lephart, S.M., 2002b. The sensorimotor system, Part II: the role of proprioception in motor control and functional joint stability. J. Athletic Train. $37,80-84$.

Robichaud, J.A., Pfann, K.D., Vaillancourt, D.E., Comella, C.L., Corcos, D.M., 2005 Force control and disease severity in Parkinson's disease. Movement Disorders: Official J. Movement Disorder Soc. 20, 441-450.

Roh, J., Rymer, W.Z., Perreault, E.J., Yoo, S.B., Beer, R.F., 2013. Alterations in upper limb muscle synergy structure in chronic stroke survivors. J. Neurophysiol. 109, $768-781$.

Roijezon, U., Clark, N.C., Treleaven, J., 2015. Proprioception in musculoskeletal rehabilitation. Part 1: basic science and principles of assessment and clinical interventions. Manual Ther. 20, 368-377.

Rose, M.H., Lokkegaard, A., Sonne-Holm, S., Jensen, B.R., 2013. Tremor irregularity, torque steadiness and rate of force development in Parkinson's disease. Mot. Control 17, 203-216.

Rueda, F.M., Montero, F.M.R., Torres, M.P.H., Diego, I.M.A., Sanchez, A.M., 2012. Page JCM (Movement analysis of upper extremity hemiparesis in patients with cerebrovascular disease: a pilot study). Neurologia 27, 343-347.

Saccol, M.F., Zanca, G.G., Ejnisman, B., de Mello, M.T., Mattiello, S.M., 2014. Shoulder rotator strength and torque steadiness in athletes with anterior shoulder instability or SLAP lesion. J. Sci. Med. Sport/Sports Med. Australia 17, 463-468.

Santos, G.L., Salazar, L.F.G., Lazarin, A.C., Russo, T.L., 2015. Joint position sense is bilaterally reduced for shoulder abduction and flexion in chronic hemiparetic individuals. Top. Stroke Rehab. 22, 271-280.

Shinohara, M., Yoshitake, Y., Kouzaki, M., Fukuoka, H., Fukunaga, T., 2003. Strength training counteracts motor performance losses during bed rest. J. Appl. Physiol. (Bethesda, Md: 1985) 95, 1485-1492.

Silva-Couto, M.A., Prado-Medeiros, C.L., Oliveira, A.B., Alcantara, C.C., Guimaraes, A. T., Salvini Tde, F., et al., 2014. Muscle atrophy, voluntary activation disturbances, and low serum concentrations of IGF-1 and IGFBP-3 are associated with weakness in people with chronic stroke. Phys. Ther. 94, 957967

Sions, J.M., Tyrell, C.M., Knarr, B.A., Jancosko, A., Binder-Macleod, S.A., 2012. Ageand stroke-related skeletal muscle changes: a review for the geriatric clinician. J. Geriatric Phys. Ther. 35, 155-161 (2001).

Slifkin, A.B., Newell, K.M., 1999. Noise, information transmission, and force variability. J. Exp. Psychol. Hum. Percept. Perform. 25, 837-851.

Sterr, A., Shen, S., Szameitat, A.J., Herron, K.A., 2010. The role of corticospinal tract damage in chronic motor recovery and neurorehabilitation: a pilot study. Neurorehab. Neural Repair 24, 413-419.

Stoeckmann, T.M., Sullivan, K.J., Scheidt, R.A., 2009. Elastic, viscous, and mass load effects on poststroke muscle recruitment and co-contraction during reaching: a pilot study. Phys. Ther. 89, 665-678. 
Taylor, A.M., Christou, E.A., Enoka, R.M., 2003. Multiple features of motor-unit activity influence force fluctuations during isometric contractions. J. Neurophysiol. 90, 1350-1361.

Thorp, A.A., Owen, N., Neuhaus, M., Dunstan, D.W., 2011. Sedentary behaviors and subsequent health outcomes in adults a systematic review of longitudinal studies, 1996-2011. Am. J. Prev. Med. 41, 207-215.

Tieges, Z., Mead, G., Allerhand, M., Duncan, F., van Wijck, F., Fitzsimons, C., et al., 2015. Sedentary behavior in the first year after stroke: a longitudinal cohort study with objective measures. Arch. Phys. Med. Rehab. 96, 15-23.

Tracy, B.L., Hitchcock, L.N., Welsh, S.J., Paxton, R.J., Feldman-Kothe, C.E., 2015. Visuomotor correction is a robust contributor to force variability during index finger abduction by older adults. Front. Aging Neurosci. 7, 229.

Triandafilou, K.M., Kamper, D.G., 2012. Investigation of hand muscle atrophy in stroke survivors. Clin. Biomech. (Bristol, Avon) 27, 268-272.

Turner, D.L., Tang, X., Winterbotham, W., Kmetova, M., 2012. Recovery of submaximal upper limb force production is correlated with better arm position control and motor impairment early after a stroke. Clin. Neurophysiol.: Official J. Int. Federat. Clin. Neurophysiol. 123, 183-192.

Vafadar, A.K. Cote, J.N., Archambault, P.S., 2015. Effectiveness of functional electrical stimulation in improving clinical outcomes in the upper arm following stroke: a systematic review and meta-analysis. BioMed Res. Int. 2015, 729768.

Verheyden, G., Nieuwboer, A., De Wit, L., Feys, H., Schuback, B., Baert, I., et al., 2007. Trunk performance after stroke: an eye catching predictor of functional outcome. J. Neurol. Neurosurg. Psychiatry 78, 694-698.

Verheyden, G., Vereeck, L., Truijen, S., Troch, M., Herregodts, I., Lafosse, C., et al. 2006. Trunk performance after stroke and the relationship with balance, gait and functional ability. Clin. Rehab. 20, 451-458.

Vilaro, J., Gimeno, E., Sanchez Ferez, N., Hernando, C., Diaz, I., Ferrerc, M., et al., 2007. [Daily living activity in chronic obstructive pulmonary disease: validation of the Spanish version and comparative analysis of 2 questionnaires]. Med. Clin. 129, 326-332.

Wilk, K.E. Andrews, J.R. Arrigo C.A. 1997. The physical examination of the glenohumeral joint: emphasis on the stabilizing structures. J. Orthopaedic Sports Phys. Ther. 25, 380-389.

Zanca, G.G., Saccol, M.F., Oliveira, A.B., Mattiello, S.M., 2013. Shoulder internal and external rotations torque steadiness in overhead athletes with and without impingement symptoms. J. Sci. Med. Sport/Sports Med. Aust. 16, 433-437.

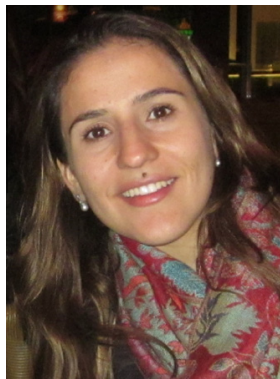

Gabriela Lopes dos Santos received her bachelor's degree and a Master's in Physical Therapy from Universidade Federal de São Carlos (Brazil), where she is currently a PhD student. Her research interests are shoulder motion analysis, electromyography, and sensorimotor control related to neurologic disorders.

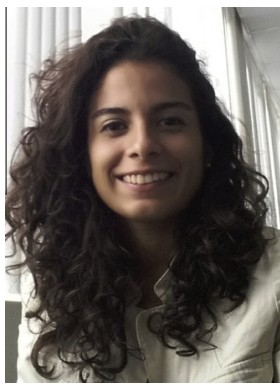

Luisa Fernanda García Salazar received her bachelor's degree in Physical Therapy from Universidad Nacional de Colombia (Bogotá, Colombia) and her Master's degree in Physical Therapy from Universidade Federal de São Carlos (Brazil). She is currently professor and researcher in the Physical Therapy Graduate Program at Universidad del Rosario (Bogotá, Colombia). Her research interests are spasticity, evidence-based rehabilitation for upper limb dysfunction and postural control related to neurological disorders

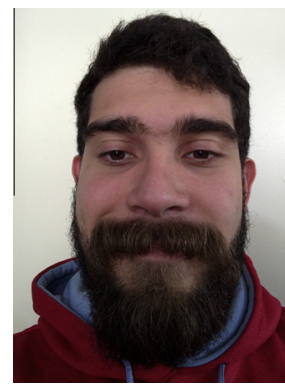

Matheus Bragança Souza Student of Physical therapy at the Universidade Federal de São Carlos (Brazil). His research interests are neurology, sensorimotor control and motion analysis.

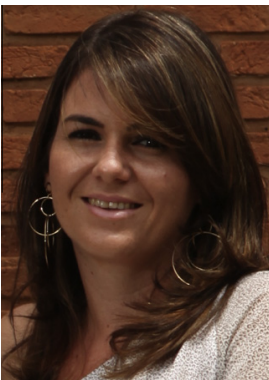

Ana Beatriz Oliveira received her bachelor's degree and a PhD in Physical Therapy from Universidade Federal de São Carlos (Brazil). She also underwent a training program in Occupational Safety and Health at the extinct Swedish National Institute for Working Life and the Royal Institute of Technology (KTH). She is currently Professor in the Physical Therapy Undergraduate and Graduate Program at Universidade Federal de São Carlos. Her research interests are application of electromyography in musculoskeletal investigations, signal processing, and physical exposure and prevention of work-related musculoskeletal disorders.

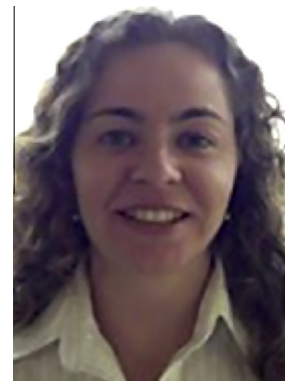

Paula Rezende Camargo received her bachelor's degree, a Master and a PhD in Physical Therapy from Universidade Federal de São Carlos (Brazil). She is currently Professor and Researcher in the Physical Therapy Graduate Program at Universidade Federal de São Carlos (Brazil). Her research interests are shoulder biomechanics and evidence-based rehabilitation for shoulder dysfunctions.

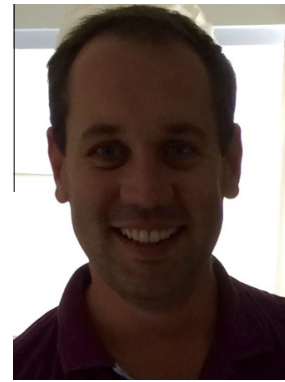

Thiago Luiz Russo received his bachelor's degree and a $\mathrm{PhD}$ in Physical Therapy from Universidade Federal de São Carlos (Brazil). He is currently Professor and Researcher in the Physical Therapy Graduate Program at Universidade Federal de São Carlos (Brazil). His research interests are sensoriomotor control, neuromuscular plasticity and neurorehabilitation. 